\title{
REVIEW
}

\section{SOFT TISSUE EPITHELIOID VASCULAR TUMORS: A PRACTICAL CLINICO PATHOLOGICAL DIAGNOSTIC APPROACH}

\author{
C. Gerosa ${ }^{1,5}$, D. Fanni ${ }^{1,5}$, E. Massa ${ }^{2}$, E. Lai ${ }^{2}$, A. Ravarino', M. Debiec-Richter ${ }^{3}$, \\ G. Faa ${ }^{1,5}$, M. Scartozzi ${ }^{2}$, R. Sciot ${ }^{4}$
}

${ }^{1}$ Division of Pathology, Department of Medical Science and Public Health, University of Cagliari, Cagliari, Italy ${ }^{2}$ Division of Oncology, Department of Medical Science and Public Health, University of Cagliari, Cagliari, Italy ${ }^{3}$ Department of Human Genetics, KU Leuven and University Hospitals Leuven, Leuven, Belgium ${ }^{4}$ Department of Pathology, KU Leuven and University Hospitals Leuven, Leuven, Belgium

${ }^{5}$ Department of Biology, College of Science and Technology, Temple University, Philadelphia, PA, USA

\section{CORRESPONDING AUTHOR:}

\section{Clara Gerosa}

Division of Pathology, Department of Medical Science and Public Health, University of Cagliari

via Università 40

09124 Cagliari, Italy

Department of Biology, College of Science and Technology, Temple University

1801 N. Broad Street, 19122 Philadelphia, PA, USA

E-mail: clarge@tiscali.it

ORCID: 0000-0003-2561-5055

Doi: $10.48286 / a r 0.2021 .26$

History

Received: Sept 26, 2021

Accepted: Nov 2, 2021

Published: Dec 1, 2021

\section{ABSTRACT}

Soft tissue epithelioid vascular tumors are characterized by a wide spectrum and represent a controversial topic for overlapping morphologic features; they require depth knowledge of the various subtypes, in order to be able to predict the clinical behaviour of the lesion. The World Health Organization (WHO) classification of soft tissue tumours recognizes multiple vascular tumours with epithelioid features, with different levels of malignancy: 1) benign neoplasms, as epithelioid hemangioma (EH) 2) tumours with an intermediate behaviour, characterized by low distant metastatic rates, including pseudomy- ogenic hemangioendothelioma (PHE); 3) malignant vascular tumours, with higher metastatic rate, as epithelioid hemangioendothelioma (EHE) and the epithelioid variant of angiosarcoma (EAS). The aim of this review is to report the most important clinical, pathological, immuhistochemical and cytogenetic features of epithelioid vascular tumours. In order to reach the correct diagnosis, the identification of epithelioid features, immunohistochemical (CD31 and ERG) and cytogenetic (CAMPTA1 and FLI1) markers are able to make more reproducible the interpretation of this complex group of soft tissue neoplasms. 


\section{KEY-WORDS}

Vascular soft tissue; epithelioid tumors; vascular tumors.

\section{INTRODUCTION}

Soft tissue vascular tumors are characterized by a wide clinical, morphologic and immunohistochemical spectrum, including hemangioma, hemangioendothelioma, angiosarcoma, and their multiple spindle and epithelioid variants. The etiology of the majority of soft tissue epithelioid vascular tumours remains unclear, mainly because of their rarity. Because of major differences in their clinical behavior and, consequently, in treatment and prognosis, distinguishing accurately the multiple vascular tumor entities represents an important challenge for pathologists in soft tissue diagnosis Within the vascular tumor spectrum, the epithelioid vascular tumors represent a complex chapter, due to their unusual and sometimes overlapping morphologic features, and to their often unpredictable clinical behavior (1). The World Health Organization (WHO) classification of soft tissue tumours $(1,2)$ recognizes vascular tumours with epithelioid features based on their distinct level of malignancy (table I):

1) benign neoplasms as epithelioid hemangioma (EH)

2) tumours with an intermediate behaviour such as pseudomyogenic hemangioendothelioma (PHE) (3), characterized by low distant metastatic rates;

3) malignant vascular tumours, including epithelioid hemangioendothelioma (EHE) with 20$30 \%$ metastatic rates and epithelioid variant of angiosarcoma (EAS), with greater than $50 \%$ metastatic rates (1).

In clinical practice, the terminology and classification applied for vascular soft tissue tumors and, in particularly, for the epithelioid variants, have proven particularly controversial due to the lack of widely recognized objective diagnostic criteria for their differential diagnosis, leading to the definition of epithelioid vascular tumours as "diagnostically challenging" (1).

All these data taken together are at the basis of some confusion that surrounds the classification

\section{IMPACT STATEMENT}

Key histologic and immnohistochemical features for a correct diagnosis of vascular epithelioid tumors.

\begin{tabular}{|l|l|}
\hline $\begin{array}{l}\text { Benign } \\
\text { neoplasm }\end{array}$ & Epithelioid Hemangioma (EH) \\
\hline $\begin{array}{l}\text { Intermediate } \\
\text { malignancy }\end{array}$ & $\begin{array}{l}\text { Pseudomyogenic } \\
\text { Hemangioendothelioma (PHE) }\end{array}$ \\
\hline $\begin{array}{l}\text { Malignant } \\
\text { neoplasm }\end{array}$ & $\begin{array}{l}\text { Epithelioid Angiosarcoma (EAS) } \\
\text { Epithelioid }\end{array}$ \\
\hline
\end{tabular}

Table I. Classification of soft tissue epithelioid vascular tumors.

of this rare subset of vascular tumours. For example, it has been claimed in the past that epithelioid hemangioma should not represent a distinct clinicopathologic entity, but rather be considered as a misdiagnosed epithelioid hemangioendothelioma, a malignant tumour. This example illustrates the need of a better and more uniform classification of soft tissue epithelioid vascular tumours, and to give more accurate prognostic data to oncologists. The recent identification of the WWTR1-CAMTA1 fusion, as the genetic hallmark of EHE, has provided an objective and powerful diagnostic tool that can be used to distinguish EH from EHE, particularly in cases where only biopsy material is available (4). The aim of this brief review is to evaluate the pathological and clinical characteristics of epithelioid vascular tumours, with the aim of giving pathologists a relatively simple approach, able to make easier and more reproducible the interpretation of this complex group of soft tissue neoplasms.

\section{EPITHELIOID HEMANGIOMA (EH)}

\section{Pathogenesis}

The pathogenesis of epithelioid hemangioma (EH) is not fully understood and has been long debated; indeed, it is unclear whether $\mathrm{EH}$ represents a benign vascular neoplasm or a reactive process to a preceding trauma. Fetsch et al. reviewed 96 cases of superficial and deep soft tissue EH, assessing if 
the lesions arose near damaged vessels and the incidence of previous trauma. In 52 cases of $\mathrm{EH}$ with an artery or vein associated with the mass, the vessel was damaged and showed fibrointimal proliferation, discontinuity of the internal elastic lamina, and/or mural disruption. 1 out of 12 patients with a previous trauma developed an arteriovenous malformation and then an $\mathrm{EH}$. Based on these findings, the Authors suggest that a significant percentage of $\mathrm{EH}$ of soft tissue arise on a reactive basis probably secondary to damage and repair of an artery or vein $(5,6)$.

\section{Epidemiology}

$\mathrm{HE}$ is most frequently present in adults, between 20 and 40 years, but the age of insurgence ranges from 7 to 81 years (table II). A female predominance has been reported (table III).

\section{Clinical features}

Most tumors occur in the head and neck region, the area around the ear representing the most typical site of EH. Other possible locations include the skin of the extremities (arms, hands, feet, tibia), followed by the trunk (ribs, vertebras, axilla, clavicle). Occasionally, EH may occur in deep soft

\begin{tabular}{|l|c|c|c|c|}
\hline & RANGE & MEAN & OCCASIONALLY & PEDIATRIC \\
\hline EH & $7-81$ & $20-40$ & & \\
\hline EHE & $>10$ & 50 & $<10$ & \\
\hline PHE & & 31 & & 1.5 months \\
\hline EAS & & 55 & & -15 years \\
\hline
\end{tabular}

Table II. Age at presentation of ephitelioid vascular tumors $(2,7)$. EH: Epithelioid Hemangioma; PHE: Pseudomyogenic Hemangioendothelioma; EHE: Epithelioid Hemangioendothelioma; EAS: Epithelioid Angiosarcoma. tissues, as well as in multiple organs, including the liver. Also, bones may be affected. Some patients present with multiple sites of involvement, more frequently in hands, in the feet and in the head and neck region. Multifocality may regard both bone and soft tissues (7) (table IV).

Erythematous skin papule or subcutaneous nodule, sometimes pruritic. In a percentage of subjects, $\mathrm{EH}$ is characterized by multiple lesions. Peripheral eosinophilia is detected in $10-20 \%$ of carriers.

\section{Histological picture}

As shown in figures 1, 2 and 3, at low power, the tumour may be centred in the dermis or in the subcutaneous fat. It shows a nodular growth pattern and well-defined pushing margins. A fibromyxoid blue-stained stroma often subdivides the proliferating lobules of proliferating vascular structures. Tumour cells may show different architectural patterns. They can be organized in large vessels, whose lumen is covered by plump cuboidal or hobnail endothelial cells (figure 1), with abundant eosinophilic or amphophilic cytoplasm. Nuclei are roundish, with homogeneous finely dispersed chromatin. Mild nuclear polymorphism may be present. Nuclear atypia is absent. Mitoses are rare or absent and atypical mitoses lack. Epithelioid tumour cells may also be arranged in poorly canalized cords or in solid sheets (figures $\mathbf{2}, \mathbf{3}$ ). The eosinophilic appear-

\begin{tabular}{|l|l|l|l}
\hline EH & EHE & PHE & EAS \\
\hline F & F & M & $\begin{array}{l}\text { M (adults) }>\text { F M } \\
\text { (children) }<\text { F }\end{array}$ \\
\hline
\end{tabular}

Table III. Gender prevalence of ephitelioid vascular tumors $(2,7)$. EH: Epithelioid Hemangioma; PHE: Pseudomyogenic Hemangioendothelioma; EHE: Epithelioid Hemangioendothelioma; EAS: Epithelioid Angiosarcoma.

\begin{tabular}{|c|c|c|c|c|}
\hline & EH & EHE & PHE & EAS \\
\hline HEAD AND NECK REGION & +++ & ++ & + & +++ (in children) \\
\hline EXTREMITIES & ++ & +++ & +++ & +++ \\
\hline TRUNK & ++ & ++ & ++ & + \\
\hline RETRO PERITONEUM/ABDOMINAL CAVITY & - & - & - & +++ \\
\hline ORGANS (liver, lungs, heart) & + & + & - & ++ (heart, thyroid, adrenal) \\
\hline BONES & - & + & + & - \\
\hline SKIN/SUPERFICIAL SOFT TISSUE & ++ & +++ & +++ & + \\
\hline DEEP SOFT TISSUE & + & +++ & - & +++ \\
\hline
\end{tabular}

Table IV. Localization of epithelioid vascular tumor $(2,7)$.

EH: Epithelioid Hemangioma; PHE: Pseudomyogenic Hemangioendothelioma; EHE: Epithelioid Hemangioendothelioma; EAS: Epithelioid Angiosarcoma. 
ance of epithelioid cells contrasts with the interposed fibromyxoid stroma. The stroma often contains lymphocytes and eosinophils. Lymphocytes may condense at the periphery of the tumour, giving rise to a dense lymphoid cuff in which germinal centers may be found; for these features, EH previously was labeled angiolymphoid hyperplasia with eosinophilia. The inflammatory infiltrate may be absent in EH. Rarely, EH appears as an intravascular tumour, appearing as a well-circumscribed solid mass with a less prominent inflammatory component. Intravascular epithelioid hemangiomas characterized by a solid architecture, with rare vascular channels. Tumour cells shows an epithelioid appearance, with clear large cytoplasm, with admixed numerous eosinophils (table $\mathbf{V}$ ).

\section{Immunohistochemistry}

SMA underlines the layer of SMA-positive pericytes surrounding the epithelioid vascular tumour cells, organized in compressed vascular structures. Immunoreactivity of epithelioid cells for cytokeratins and EMA, when present, is focal but they are typically immunoreactive for CD31(figure 4) and for ERG (8). FOSB expression can be seen as well (9-11) (table VI).

\section{Genetics}

One third of cases of classical epithelioid hemangioma are characterized by FSO/FSOB rearrangements (12). Recently, a cellular variant has been described, showing a FOSB (19q13.2) involvement (13) (table VII).

\section{Differential diagnosis}

The main differential diagnosis is with epithelioid

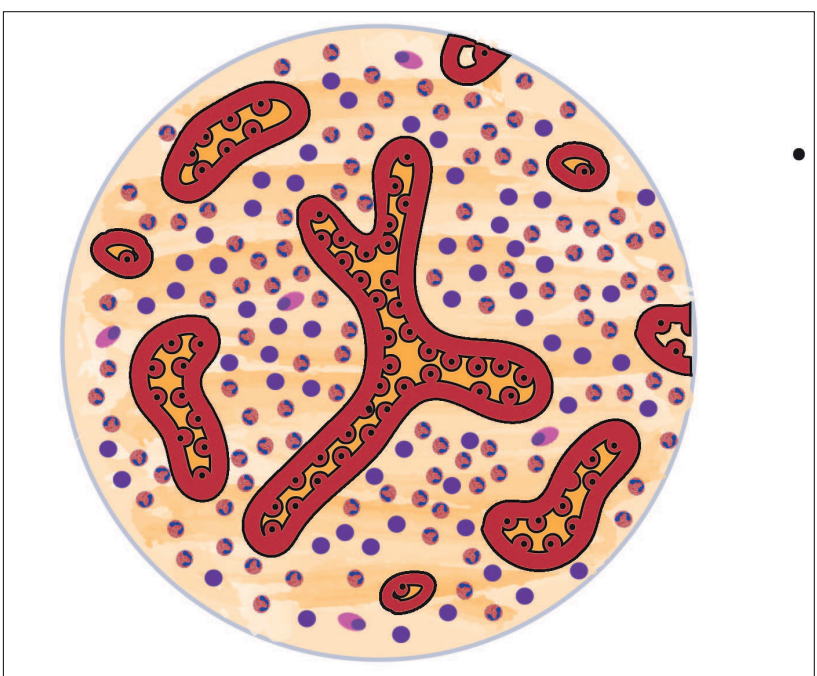

Figure 1. EH: schematic representation shows large vessels with lumen covered by plump cuboidal or hobnail endothelial cells. angiomatous nodule, epithelioid hemangioendothelioma, and epithelioid angiosarcoma (7). Epithelioid angiomatous nodule (EAN) is negative for FOSB, a marker expressed by $\sim 50 \%$ of epithelioid hemangiomas $(11,10)$. EHE shows characteristic myxochondroid matrix, cord-like growth pattern, and the absence of overt vasoformation (14). Epithelioid angiosarcoma has an architecturally complex vessels lined by atypical epithelioid endothelial cells (15)

\section{Prognosis}

$\mathrm{HE}$ is generally considered a benign lesion, but recurrences are not rare, representing about 30-50\% of cases. Its metastatic potential is generally considered to be absent, even though in one case a lymph node micro metastasis has been reported.

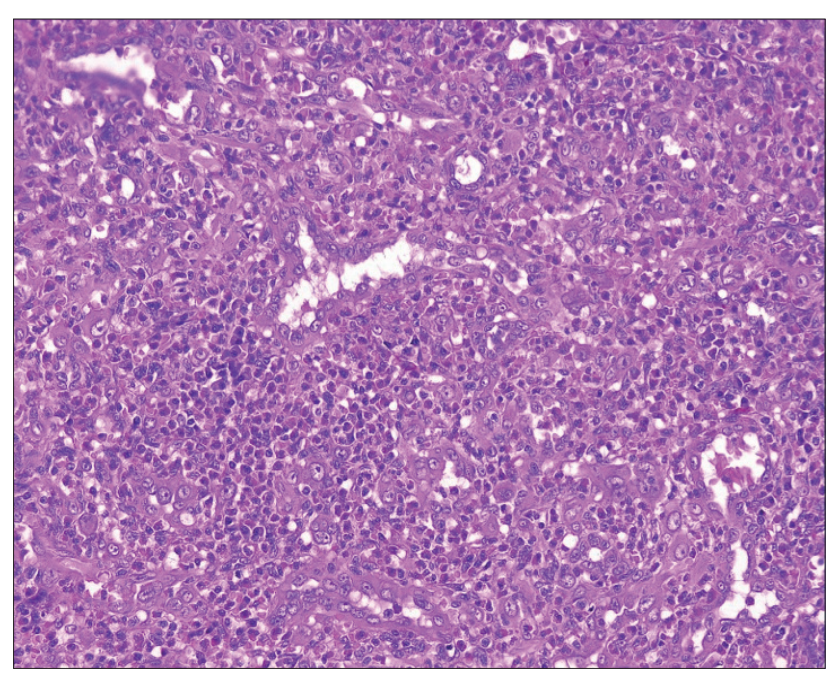

Figure 2. EH (E-E 2OHPF): tumour cells may arranged in poorly canalized cords or in solid sheets; lymphocytes and eosinophils in stroma



Figure 3. EH (E-E4OHPF): nuclei are roundish, with homogeneous finely dispersed chromatin. Mild nuclear polymorphism. Nuclear atypia is absent 


\begin{tabular}{|c|c|c|c|c|c|c|c|}
\hline & $\begin{array}{c}\text { LOBULAR } \\
\text { PROLIFERATION }\end{array}$ & $\begin{array}{c}\text { SOLID } \\
\text { SHEET-LIKE } \\
\text { PROLIFERATION }\end{array}$ & $\begin{array}{l}\text { CORD-LIKE/NEST } \\
\text { GROWTH PATTERN }\end{array}$ & \multicolumn{2}{|c|}{$\begin{array}{c}\text { WELL } \\
\text { FORMED } \\
\text { VASCULAR } \\
\text { CHANNEL }\end{array}$} & $\begin{array}{l}\text { INFLAMMATORY } \\
\text { INFILTRATE }\end{array}$ & $\begin{array}{l}\text { MYXO-HYALINE } \\
\text { MATRIX }\end{array}$ \\
\hline EH & + & N & N & \multicolumn{2}{|c|}{+} & $+*$ & N \\
\hline PHE & $\mathrm{N}$ & + & N & \multicolumn{2}{|c|}{ N } & $+* *$ & $\mathrm{~N}$ \\
\hline EHE & N & N & + & \multicolumn{2}{|c|}{ N } & N & + \\
\hline EAS & N & + & N & \multicolumn{2}{|c|}{ v } & N & N \\
\hline & $\begin{array}{l}\text { BLISTER } \\
\text { CELLS }\end{array}$ & NUCLEAR ATYPIA & \multicolumn{2}{|c|}{ INFILTRATIVE MARGINS } & & H MITOTIC RATE & ATYPIC AL MITOSES \\
\hline EH & N & N & \multicolumn{2}{|l|}{ N } & & v & N \\
\hline PHE & v & $+^{\circ}$ & \multicolumn{2}{|l|}{+} & & $\mathrm{N}$ & $\mathrm{N}$ \\
\hline EHE & + & $+^{\circ}$ & \multicolumn{2}{|l|}{+} & & N & $\mathrm{N}$ \\
\hline EAS & + & $+\infty$ & \multicolumn{2}{|l|}{+} & & + & + \\
\hline
\end{tabular}

Table V. The most important distinguishing histological features of epithelioid vascular tumors $(2,7)$.

EH: Epithelioid Hemangioma; PHE: Pseudomyogenic Hemangioendothelioma; EHE: Epithelioid Hemangioendothelioma; EAS: Epithelioid Angiosarcoma; V: variable; N: not a halmark. ${ }^{*}$ Eosinophilis and Lymphocytes; ${ }^{* *}$ Neutrophili; ${ }^{\circ}$ Mild-Moderate; ${ }^{\circ}$ Moderate-Severe.

\begin{tabular}{|l|l|l|l|l|l|l|l|l|l|l|}
\hline \multicolumn{1}{|c|}{ CK CD34 } & ERG & FLI1 & CD31 & INI1 & CD30 & GATA3 & SMA & D2-40 & PR & CAMTA1 \\
\hline EH -I+ + & ++ & + & ++ & + & - & - & ++ & - & - & - \\
\hline PHE +- & + & + & $+/-$ & + & - & - & - & - & - & - \\
\hline EHE -I+ + & ++ & ++ & ++ & + & - & - & - & - & - & + \\
\hline EAS -/+ -/+ & ++ & ++ & ++ & + & $-/+$ & $-/+$ & - & $-/+$ & - & - \\
\hline
\end{tabular}

Table VI. The most important distinguishing immunohistochemical features of epithelioid vascular tumors $(2,7)$.

EH: Epithelioid Hemangioma; PHE: Pseudomyogenic Hemangioendothelioma; EHE: Epithelioid Hemangioendothelioma; EAS: Epithelioid Angiosarcoma.

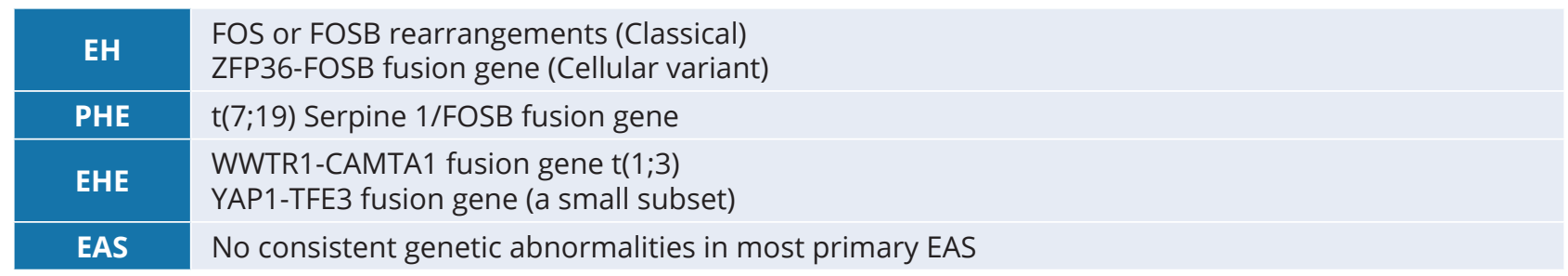

Table VII. The most important distinguishing genetic hallmarks of epithelioid vascular tumors $(2,7)$.

EH: Epithelioid Hemangioma; PHE: Pseudomyogenic Hemangioendothelioma; EHE: Epithelioid Hemangioendothelioma; EAS: Epithelioid Angiosarcoma.

Local recurrence of HE or lymph node involvement is a rare complication after incomplete resection of the tumour (16). Lesions in bone are often more aggressive and are of intermediate grade.

\section{Therapy}

Given that EH does not metastasize tumor excision with broad margins is considered the treatment of choice (14). Other local treatment options include laser cauterization, diathermy, cryotherapy, intralesional injections of corticosteroids and radiotherapy, depending also on the site of EH occurrence $(17,18)$.

\section{EPITELIOID \\ HEMANGIOENDOTHELIOMA (EHE)}

\section{Pathogenesis}

Etiologic factors in EHE have not been established yet. The role of radiation treatment was assessed. Irradiation might indeed induce a oncogenic effect both directly and indirectly, through prolonged tissue repair stimulation, as a consequence of irradiation-induced vascular changes and tissue damage (19). In 1989, Akosa et al. described the 
EHE occurrence in the terminal ileum of a patient who had received radiotherapy for cervical cancer treatment (20). Another case of post-radiation EHE concerns a 28-year-old female patient who had received radiotherapy (total dose: 30 Gray) 18 years earlier for a recurrent congenital subcutaneous hemangioma of the lower leg (19). Hahn et al. reported the case of a woman with breast cancer and post-resection radiotherapy history who developed an EHE of the chest wall skin 3 years after the radiotherapy completion. Molecular analysis showed the presence of the typical WWTR1-CAMTA1 fusion gene. According to the authors, this finding does not validate radiation as a causality factor of oncogenesis, but at the same time an association between breast skin radiation and occurrence of EHE cannot be excluded (21).

The association with occupational factors has been suggested for EHE. Attanoos et al. described three cases of pleural EHE occurring in patients who had a history of professional exposure to asbestos. These subjects had a latency period from exposure to tumour occurrence which was similar to that seen in asbestos-related mesotheliomas, ranging from 18 to 60 years (22).Occupational exposure to vinyl chloride has also been suggested as an etiologic agent of $\mathrm{EHE}$, with a not negligible number of case reports available in literature $(23,24)$.

The hormonal influence was considered as a potential etiologic factor for liver EHE due to its higher rate in the female sex in child bearing age; moreover, an association with hormonal treatment and oral contraceptive use was also suggested $(25,26)$. However, this does not explain the cases of EHE in males and children (25). Other authors have cor-

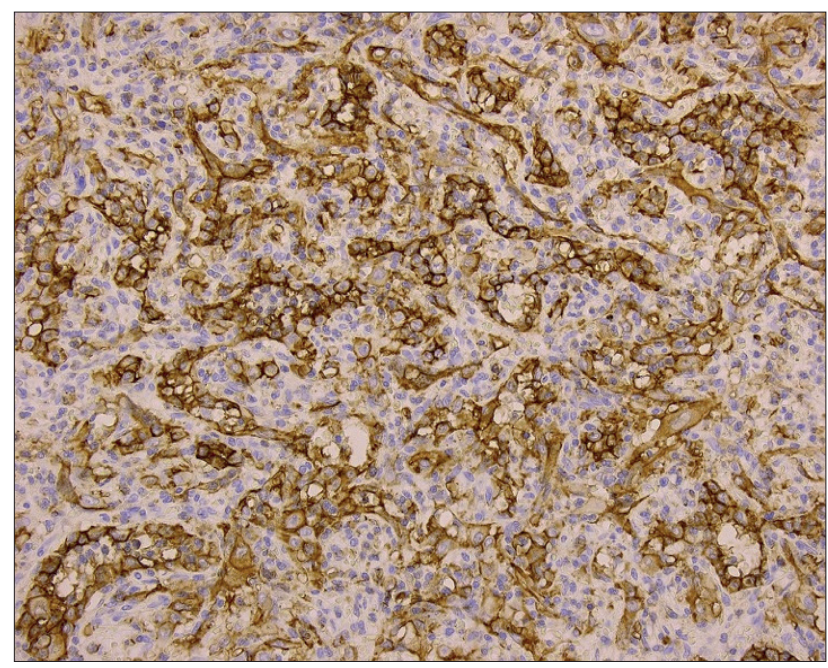

Figure 4. EH (4OHPF): Immunoistochemistry expression of CD 31 related EHE with viral hepatitis or major trauma or with occupational exposure to vinyl chloride. Viral hepatitis (HBV and HCV) have also been taken into consideration as well as occupational vinyl chloride exposure $(25,27,28)$. Despite these hypothesis and literature reports, the exact pathogenesis of EHE has not been clearly defined yet and requires further investigation.

\section{Epidemiology}

EHE mainly affects young and adults, with a mean age of 50. Even though the majority of documented cases of EHE arise in adults, EHE has even been reported even in children of less than 10 years (29) (table 2). EHE occurs more frequently in female (table III).

\section{Clinical features}

EHE may occur anywhere in the body. It may rise in deep soft tissues or in the skin. The extremities are the principal site of origin, accounting for about $60 \%$, followed by head and neck, trunk and mediastinum. In about $10 \%$ of cases, EHE originates in the oral cavity, as well as in multiple organs including bones, lungs, breast, liver, brain, and lymph nodes. EHE may be multicentric (7) (table IV).

EHE when localized in the skin, EHE appears as an exophytic dermal nodule which develops, in about $50 \%$ of cases, near a large vein.

\section{Histological picture}

At low power, the typical appearance of EHE is characterized by large epithelioid cells arranged in nests, cords and laminae embedded in an abundant myxohyaline or dense sclerotic stroma. Tumour margins are clearly infiltrative. At higher power, tumour cells show an abundant glassy eosinophilic cytoplasm, and cell borders are often very well defined. Nuclei are round or oval, vesicular, and characterized by an evident nucleolus. A convincing vasoformative character usually lacks, but single tumour cells often show vacuoles. These vacuoles are considered a sign of incomplete vascular differentiation of tumour cells (figure 5). Nuclear atypia is often absent or, more rarely, mild, evidenced by dark polydimensional and polymorphic nuclei (table V).

\section{Immunohistochemistry}

The tumor cells are immunoreactive for CD31, CD34, ERG and FLI1. Keratin expression can be seen as well. SMA positive cuffs are usually lacking. Recently, nuclear expression of CAMTA1 has 
been identified in the majority of EHE cases. Given that other epithelioid mesenchymal neoplasms are negative for CAMTA1, immunohistochemistry for CAMTA1 represents a new useful tool in distinguishing EHE from other histologic mimics, including multiple benign epithelioid vascular tumors, epithelioid angiosarcoma, and epithelioid sarcoma (30). Although all of the EHEs are CAMTA1-positive at immunohistochemistry, less than $30 \%$ of EHES show nuclear immunostaining for TFE3. Accordingly, two clinically distinct subgroups of EHEs, TFE3-positive and TFE3-negative have been identified. TFE3-positive EHEs are more vasoformative and associated with high-grade nuclear atypia and hypercellularity than TFE3-negative EHES (31) (table VI).

\section{Genetics}

EHE is characterized by recurrent translocations involving chromosomal regions 1 p36.3 and 3q25, $t(1 ; 3)(p 36.3 ; q 25)$, resulting in the formation of a WW domain-containing transcription regulator 1 (WWTR1) (3q25) and calmodulin-binding transcription activator 1 (CAMTA1) fusion gene in approximately $90 \%$ of cases (32). A small subset of EHE is characterized by a Yes associated protein 1(YAP1)-transcriprion factor E3 (TFE3) fusion gene (31) (table VII).

\section{Differential diagnosis}

EHEs are frequently confused with nonendothelial tumours, such as carcinomas and melanoma but these cases are negative for endothelial markers. Epithelioid sarcoma and epithelioid hemangioendothelioma can show significant immunophenotypic overlap but epithelioid sarcoma have a multinodular architecture. EAS show important cytologic atypia, pleomorphism, and higher mitotic activity (14). At immunohistochemistry analysis, nuclear expression for CAMTA1 is sensitive and highly specific for diagnosis of EHE(33)

\section{Prognosis}

Complete resection of EHE is generally associated with good outcome. Natural evolution of paediatric visceral $\mathrm{EHE}$, including liver and lung $\mathrm{EHE}$, is variable, and long-term prognosis remains unclear. In a recent multivariate analysis of 51 cases of EHE, size greater than $3 \mathrm{~cm}$ and greater than mitotic figures per 50 HPFs predicted an adverse outcome; atypia was not an independent adverse factor (3436). In an other study, Shibayama demonstread

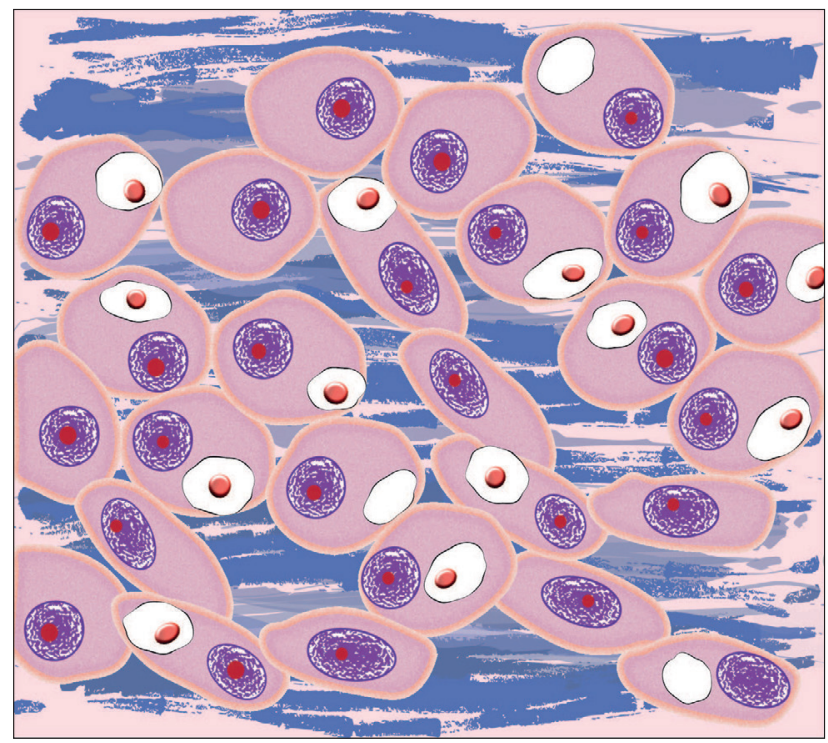

Figure 5. EHE: schematic drawing shows large epithelioid cells embedded in an abundant myxohyaline or dense sclerotic stroma.

that a subset of EHE with aberrant expression of Sinaptophysina may have a potential aggressive diagnostic implication (36).

\section{Therapy}

Treatment options include observation, preoperative embolization, surgical resection followed by radiotherapy and/or chemotherapy (24), immunotherapy, targeted therapy, chemotherapy and radiotherapy and should be adapted to the primary site of the tumour. Observation is reserved for indolent EHE, for patients who are not surgical candidates due to comorbidities or technical challenges and for those with asymptomatic locoregional or systemic metastatic disease (37). Surgical resection should be performed when possible and should be done in referral centers with experience of sarcoma surgery. EHE should be resected en bloc and a cuff of normal tissue around the tumor surface should be left, in order to obtain R0 margins and minimize the risk of local recurrence (38). As for hepatic $E H E$, surgical resection is the treatment of choice for stable/slowly progressing unifocal or limited locoregional, technically resectable lesions and it is curative in at least half of patients. Liver transplantation should be proposed to unresectable EHE patients and for those who develop tumour-related liver failure but who are in generally good conditions. Other therapeutic options for patients with unifocal disease but who are not candidates for surgery and for those with recurrent liver nodules after liver resection or transplantation and/or as a 
bridge to liver transplantation are represented by stereotactic body RT (SBRT), radiofrequency ablation (RFA) and microwave ablation (MWA).

The role of radiotherapy as primary treatment is not yet defined, and radiotherapy is restricted to partially resected lesions with positive margins (adjuvant total dose of 60 Gy in 30 fractions) (39). In patients with localized and resectable EHE there is no evidence for systemic treatment in the (neo) adjuvant setting (37). As for aggressive $\mathrm{EHE}$, various strategies have been retrospectively reported to have antitumor activity, including interferon, thalidomide, multi-tyrosine kinase inhibitors with strong vascular endothelial growth factor receptor inhibitory property (sorafenib, pazopanib), and sirolimus (40). Unfortunately, a standard medical approach has not been established yet. No phase III randomized studies have been conducted and the results from only two phase II trials have been reported. In the study by Agulnik et al., the effect of bevacizumab, a recombinant humanized antibody against vascular endothelial growth factor (VEGF), was assessed in angiosarcoma and EHE; seven patients with EHE were included, of which two had partial response (PR) and four had stable disease (SD) (41) In the phase II study of the French Sarcoma group testing the effect of sorafenib in sarcoma patients, 15 patients with EHE were included; only two had PR and five had SD (42). Due to the rarity of these tumors, most data derive from case-reports and small case-series and this is why a standard of care has not been yet defined. Conventional chemotherapy that is usually administered for soft tissue sarcoma has shown very limited activity (38). A retrospective international case series from the World Sarcoma Network aimed to assess the activity of systemic therapies in advanced EHE. Globally, 73 patients were included in this observational study. Of them, 21 received more than one treatment. Thirty-three patients were treated with anthracyclines-based regimens; $3 \%$ achieved PR, 76\% SD, 21\% developed progressive disease (PD). Median progression free survival (PFS) was 5.5 months and median overall survival (OS) was 14.3 months. Eleven patients received paclitaxel and obtained PR in 9\% of cases, SD in 55\% and PD in 36\%; median PFS and median OS were 2.9 and 18.6 months, respectively. Of the twelve patients who were administered pazopanib, 25\% achieved SD and 75\% PD; median PFS was 2.9 months and median OS was 8.5 months. Fifteen patients received interferon- $a 2 b$, achieving $7 \% P R$, 73\% SD, 20\% PD; median PFS and median OS were
8.9 and 64.3 months, respectively. 27 patients were treated with other regimens; among them, 1 PR (ifosfamide) and 9 SD (5 gemcitabine plus docetaxel, 2 oral cyclophosphamide, 2 others) were reported. This analysis confirmed that systemic therapies available for advanced sarcomas have limited activity in EHE (43). For these reasons and for the lack of robust evidence, chemotherapy should be reserved to more aggressive or rapidly progressive EHE with similar behavior to high-grade sarcoma (38). Among new agents, the highest clinical activity has been reported for mammalian target of rapamicine (mTOR) inhibitors. These drugs showed a PFS of 1 year and an OS of 2 years; moreover, 10\% of patients reach a longer PFS. Three out of $24 \mathrm{EHE}$ patients aged 2-26 years of a multi-institutional case series treated with sirolimus obtained stable disease or a partial response for more than 2.5 years (44). The Italian Rare Cancer Network reported a retrospective series of 38 adult EHE patients who received treatment with continuous dosing sirolimus, $5 \mathrm{mg}$ daily. All patients had a disease progression in the previous six months. At median follow up of 41.5 months (interquartile range [IQR], 23.9-56.8 months), the median PFS was 13 months $(95 \% \mathrm{Cl}, 3.7$ months to not estimated [NE]), and the median OS was 18.8 months $(95 \% \mathrm{Cl}, 10.6$ months to NE). Median PFS was 4.8 months (IQR, 3.5-11.7 months) in patients with serosal effusions at baseline versus 47.8 months (IQR, 11.4 months to NE) in those without this clinical manifestation; data for OS were consistent (median OS 10.6 months [IQR, 5.1-13.0 months] versus 47.8 months [IQR, 15.7 months to NE]. Globally, sirolimus was well tolerated; irregular menstruation/ovary disfunction was observed in 10 patients. Sirolimus led to prolonged SD in most patients without serosal effusions, whereas it showed limited activity in EHE with serosal effusion (45). For these reasons, mTOR inhibitors represent so far the preferred treatment options for patients with advanced and moderately progressive disease (38).

A 62-year-old woman with metastatic pulmonary EHE was successfully treated with pazopanib, which provided prolonged stable disease for up to 24 months (46). Other reported agents used in pulmonary EHE comprise chemotherapy regimens and target agents, alone or in combination. Most data derive from case reports and no consensus has been reached on the best treatment. Indeed, all these agents have been investigated alone or in combination, without showing exciting results, as 
well as radiotherapy. Therefore, the identification of an effective treatment strategy in this disease is a urgent medical need. Among the combinations of various drugs, it is of notice the association of apatinib, a selective VEGF receptor-2 (VEGFR-2) inhibitor, and chemotherapy. In a 64-year-old female patient with EHE of the lung, four cycles of apatinib combined with doxorubicin/cyclophosphamide were administered with stabilization of multiple bilateral nodules and significant improvement of disease-related symptoms such as chest tightness, chest pain and cough. Since the patient did not tolerate the combination treatment (due to nausea and neutropenia grade 3-4), chemotherapy was interrupted and she continued with apatinib monotherapy; the disease remained stable at a follow up of after 24 months (48).

For the most aggressive EHE, angiosarcoma-type chemotherapy remains an option; for aggressive hepatic EHE with or without metastatic lesions, liver transplant has also been performed in pediatric patients (49). Recently, a targeted radionuclide therapy has been proposed for metastasizing EHE (28). Moreover, data obtained from the genomic analysis of EHE using next-generation sequencing (NGS) have been shown to be significant for the planning and monitoring of treatment for this entity (29). However, to date, no standard agents demonstrated clinically significant activity, so the best option is to strongly encourage these patients to participate in clinical trials.

\section{WPSEUDOMYOGENIC HEMANGIOENDOTHELIOMA (PHE).}

\section{Pathogenesis}

PHE is characterised by peculiar gene fusions involving FOSB gene with SERPINE1, ACTB, or WWTR1 (50). Ye et al. reported a case of PHE secondary to fibrous dysplasia of the left lower extremity in a 14-year-old female (51). However, due to the extreme rarity of this tumour, no sure data on etiologic factors are available.

\section{Epidemiology}

$\mathrm{PHE}$ is a typical tumour of young adults, with a mean age at presentation of 31 years. A wide age category may nevertheless be affected, including 12 year-old children (52) (table VII). PHE is a typical soft tissue tumour of males, with a M/F ratio 5/1 (table III).

\section{Clinical features}

PHE presents as single, but more often as multiple dermal/subcutaneous nodules, in the lower limbs (54\%), upper limbs (24\%) and trunk (18\%). Less frequently, PHE is localized in bones (14\%) or in head and neck (4\%) (table IV). Because of multifocality in $2 / 3$ of patients, a PET scan is indicated to visualize clinically occult deep lesions (7). At clinical examination, a single subcutaneous nodule or, in $66 \%$ of patients, multiple nodules, that may be painful or painless, characterize the clinical picture. The skin of the lower limbs is the preferential localization. Nodules may be superficial, centred in the dermis, or subcutaneous. In about $50 \%$ of patients, additional tumoral nodules may be present in muscles and, in a minority of cases, bony lesions may be detectable at radiology.

\section{Histological picture}

PHE appears as a nodular lesion with irregular infiltrative margins, with tumour cells extending into the surrounding dermis and in the subcutaneous fat tissue. A plexiform pattern may be occasionally observed. Regarding the architectural pattern, tumour cells are arranged in short irregular fascicles and sheets. Multiple cell types may be observed in PHE. The majority of tumour cells are characterized by a spindle nucleus and by and abundant eosinophilic cytoplasm. A minority of cells show a polygonal shape and an epithelioid morphology. Scattered cells show a rhabdomyoblast-like appearance, with abundant eosinophilic cytoplasm displacing the nucleus at the periphery of the cell. Nuclei are vesicular, with evident or prominent nucleoli. A prominent inflammatory intratumoral infiltrate, mainly of neutrophilic PMN, is detectable in about half of cases. Mitoses are rare (9) (figures

\section{$6,7)$ (table V).}

\section{Immunohistochemistry}

The immunohistochemical pattern is characterized by a strong diffuse cytoplasmatic reactivity of tumour cells for cytokeratins (AE1/AE3) (figure $8 \boldsymbol{a}$ ) and by a diffuse nuclear staining for ERG (figure 8 b) and FLI1. INI1 reactivity is conserved in tumour cells. Focal staining for CD31 is observed in $50 \%$ of cases, whereas only a minority of cases show focal immunostaining for EMA and SMA. FOSB immunohistochemistry can be a useful adjunct (10) because diffuse nuclear immunoreactivity for FOSB was demonstrated in $96 \%$ of $\mathrm{PMH}$ (53) (table VI). 


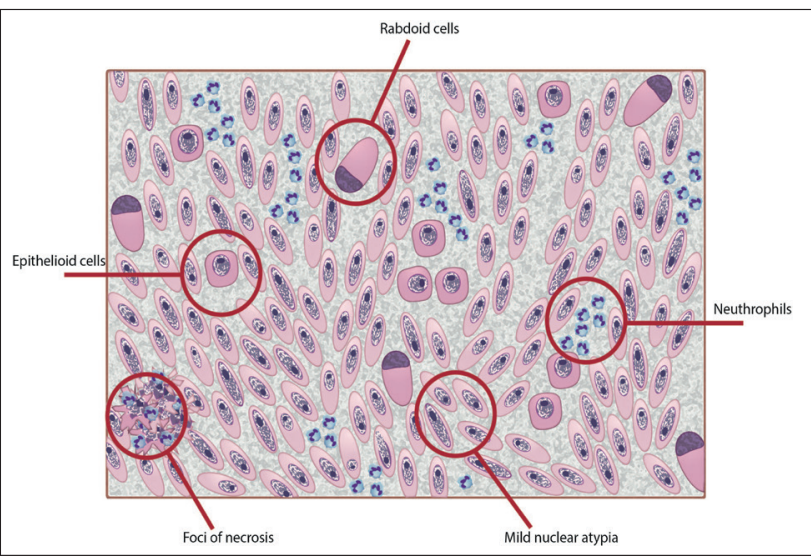

Figure 6. PHE: schematic drawing shows characteristic features of PHE.

\section{Genetics}

Recently, molecular studies aimed at revealing a putative fusion gene characteristic of this tumour entity revealed, that the sole cytogenetic change $t(7 ; 19)(q 22 ; q 13)$ results in fusion of SERPINE1 and FOSB genes (54). Given that this fusion gene has not been described in other soft tissue tumours, the detection of SERPINE1/FOSB fusion gene is considered diagnostic for PHE (table VII).

\section{Differential diagnosis}

The main differential diagnosis is epithelioid sarcoma which is characterized by the absence of INI1 expression. Pseudomyogenic hemangioendothelioma is positive for AE1/AE3, CK7, vimentin, CD31, FLI-1, ERG, and INI-1 (55). Another differential diagnosis is with leiomyosarcoma or rhabdomyosarcoma but pseudomyogenic hemangioendothelioma lacks expression of myogenic markers (14).

\section{Prognosis}

The prognosis of PHE is generally good, even though recurrences may present after resection of the nodule(s) in 2/3 of patients. Less frequently, metastases to loco-regional lymph nodes have been reported. A rare case of PHE with distant metastases, occurring 16 years after presentation, has been reported (3). Only 3 cases of PHE with distant metastases, occurring 4, 8.5, and 16 years after initial diagnosis, has been reported (52). Possible prognostic factors to predict recurrence and metastasis include multifocality, age at presentation, gender, and size of the lesion(s) (56).

\section{Therapy}

This malignancy is characterised by an indolent behaviour, with high rate of local recurrence and low

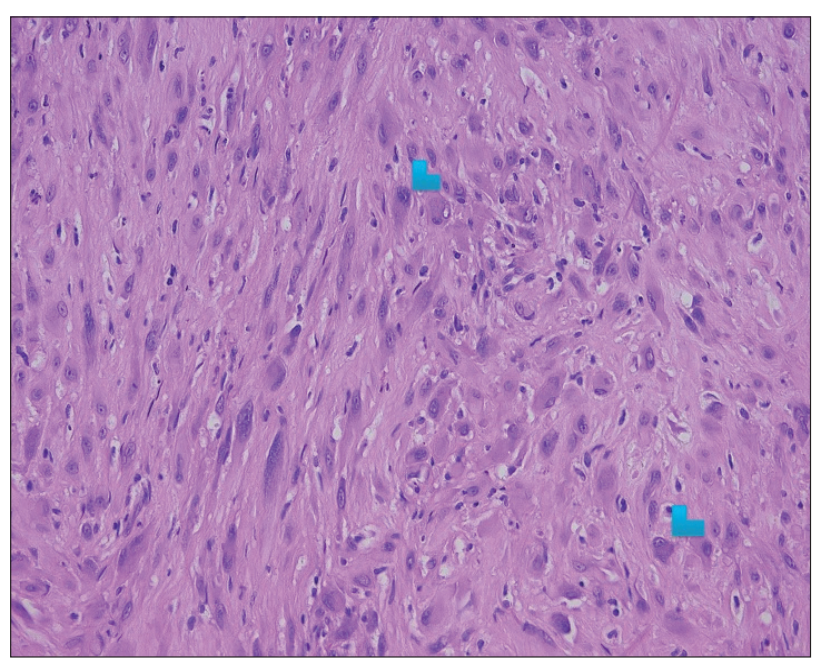

Figure 7. $P H E(H E, 4 O H P F)$ : histological picture with rhabdomyoblastlike cells (arrowheads).

risk for metastasis after surgical resection. A conservative surgical approach is generally considered the best therapeutic option in PHE. The multifocality, associated with deep extension of the tumour into the subcutaneous tissue and the underlying muscles may be at the basis of a more aggressive surgical approach. As for medical treatment, PHE does not benefit significantly from chemotherapy and radiotherapy, suggesting a marginal role of these two strategies in the control of this disease. Wei et al. reported data on 13 patients who had received adjuvant treatment (chemotherapy or radiotherapy) after surgery; $38.5 \%$ of them experienced disease progression (57). Only very few cases of response of PHE to chemotherapy have been reported in literature and no guidelines are available regarding chemotherapy selection for adults and children. Joseph et al. described the case of a 45-year-old man with PHE of the right ilium who was treated firstly with intra-arterial cisplatin (120 mg/sqm) every 3 weeks, then switched to intravenously administration with slow infusion rate due to hearing loss. PET-CT scan showed a minor response to cisplatin but since the hearing loss worsened, the patient was administered the combination of gemcitabine (900 mg/sqm) plus docetaxel (100 mg/sqm) every 3 weeks. Re-evaluation with PET-CT showed a significant response to chemotherapy. The treatment was stopped because of pulmonary toxicity; when disease progression occurred, the patient was treated with paclitaxel $80 \mathrm{mg} / \mathrm{sqm}$ for 4 months and he achieved disease stabilization for 16 months after treatment interruption (58). A 36-year-old man with multiple lesions related to PHE in the right lower leg 


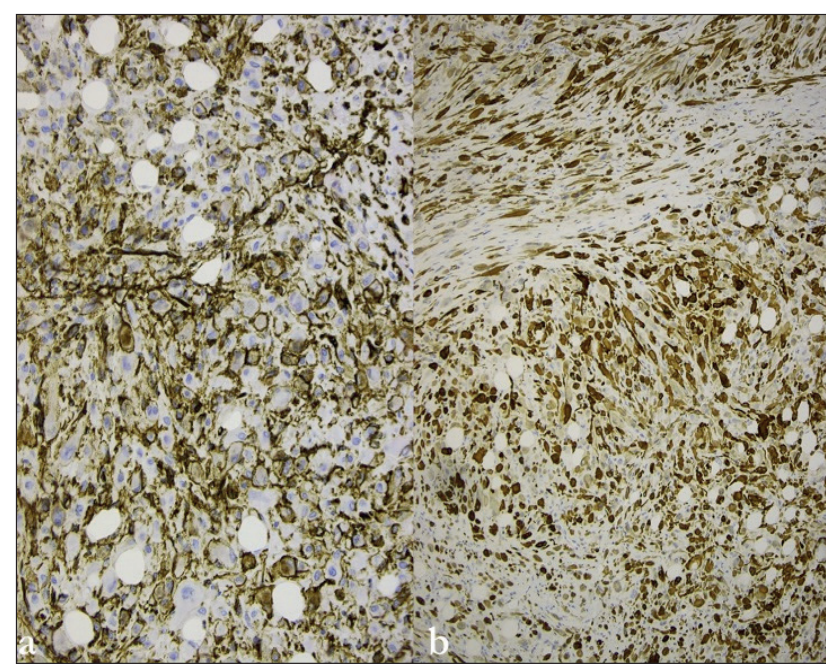

Figure $8 \boldsymbol{a}$. PHE: Immunoistochemistry expression of $C D \quad 31 ; \boldsymbol{b}$. Immunoistochemistry expressionof Keratin.

was treated with isolated limb perfusion (melphalan and TNFa) followed by four cycles of ifosfamide plus doxorubicin and hyperthermia, which led to SD. In a 22-year-old male patient with multiple PHE lesions in the thigh, which were not amiable with surgery, after failure of gemcitabine-docetaxel combination, treatment with doxorubicin $(90 \mathrm{mg} / \mathrm{sqm}$ as a continuous infusion over 72 hours) and cisplatin (120 mg/ sqm as an intravenous infusion over 4 hours), was administered. Dose-adjustment was required after the occurrence of mucositis, tinnitus, neutropenic fever and ototoxicity with the first cycle; so cisplatin was reduced to $100 \mathrm{mg} / \mathrm{sqm}$ as a slow infusion over 24 hours and doxorubicin was changed to bolus with dexrazoxane $(90 \mathrm{mg} / \mathrm{m} 2)$ every 3 weeks. SD was achieved and the patient underwent surgery (58). A 30-year-old man with PHE of lower limb, in an effort to preserve his leg, was treated for 10 months (until he became not compliant) with metronomic oral cyclophosphamide plus prednisolone. The size of the lesions decreased and no new lesions occurred (59). Two inhibitors of the mammalian target of rapamycin (mTOR), namely everolimus and sirolimus, were attempted in PHE patients, based on the association between defects in the mTOR growth control pathway and PHE (60). Everolimus was administered to a 15-year-old child, showing improvement of symptoms and tumour regression (61). In a 22-year-old patient with PHE harbouring TSC1 mutation, thirdline treatment with everolimus provided a noticeable response in the metastases in the supra-acetabular region of the left iliac bone (58). Moreover, a 51-yearold woman with recurrent PHE and mutation of SKP2, a negative regulator of the mTOR complex, was treated with everolimus and achieved disease stabilisation for a year (57). Sirolimus was administered to a 9-year-old child and led to significant clinical improvement and stabilization of tumor lesions, with an acceptable safety profile (60). Another case-report regards a 17-year-old patient with advanced, unresectable PHE, treated with telatinib, an orally available multi-tyrosine kinase inhibitor targeting VEGFR, platelet derived growth factor receptor (PDGFR), and KIT. The patient received telatinib for 9 years after diagnosis and obtained durable complete remission, being disease-free for 4 years after treatment stop. Telatinib was well tolerated; the patient reported no adverse events other than headache (62). Therefore, targeted therapy seems promising in PHE patients, especially after disease recurrence, but requires further research with prospective, larger trials

\section{EPITHELIOID ANGIOSARCOMA (EAS)}

\section{Pathogenesis}

EAS is rare, high grade malignant vascular neoplasms (63). In the majority of cases, the aetiology still remains unknown. Radiotherapy associated EAS has been reported in the urinary bladder and prostate (64); moreover EAS has been associated to chronic lymphedema of congenital origin (65) EAS of the liver has been associated to occupational exposure to thorium dioxide colloid (thorotrast) and vinyl chloride up to one fourth of the cases (66, 67). In a review of 25 sarcoma patients (16 intrahepatic and 9 extrahepatic), 1 subject with hepatic angiosarcoma had a history of industrial exposure to vinyl chloride monomer for nine months 5 years before developing the tumour (68).

Both treatment with arsenic salts and environmental/professional exposure to arsenic (especially of vineyard cultivators) have been related to EAS occurrence $(69,70)$. Salgado et al. published the case of hepatic EAS treated with Neosalvarsán (dioxidiaminoarsenobenzol) 46 years before and previous reports include 6 cases related with treatment with arsenic salts and 4 cases of arsenic environmental exposure (69). Livatidou et al. reported the case of EAS developed in the adrenal gland in a vineyard cultivator who had been exposed to arsenic-containing insecticides for over 20 years (70).

Copper exposure has been suggested to be a predisposing/etiologic factor for EAS occurrence through the same mechanism as arsenic, namely 
by hyperplasia of the hepatocytes and of the sinusoidal endothelia, dilation of the sinusoids, fibrosis of the portal spaces and/or cirrhosis, idiopathic portal hypertension and finally malignant transformation of the hyperplastic endothelia $(70,71)$.

The use of androgenic steroids was also associated to occurrence of liver EAS. More specifically, long-term use of androgenic-anabolic steroids is considered to be the fourth cause of $\operatorname{EAS}(72,73)$. However, in the majority of cases, EAS's etiology still remains unknown.

\section{Epidemiology}

Middle-aged and elderly adults (mean 55 years) are mainly affected. Paediatric cutaneous angiosarcoma show predominantly an epithelioid morphology (80\%), patient ages ranging from 1.5 months to 15 years (74). Contrasting with adults in whom males are preferentially involved, paediatric epithelioid angiosarcoma preferentially affects female children (table II), with a F/M ratio of 8/2(74) (table III).

\section{Clinical features}

EAS most often arises in the deep soft tissues of the lower extremities (60\%), followed by the retro peritoneum and the abdominal cavity. The localization in the superficial soft tissues and in the skin is rare (75). Organs (heart, thyroid, adrenal) are not rarely involved. In children, preferred locations for EAS are the skin of head and neck (paediatric cutaneous epithelioid angiosarcoma) and mediastinum (76) (table IV). Angiosarcoma may also present in the liver in paediatric patients (77).

Paediatric cutaneous epithelioid angiosarcoma predominantly presents in teeth skin of the lower extremities, being commonly associated with a pre-existing condition, including congenital lymphedema, and congenital hemangioma treated with radiation therapy (74).

\section{Histological picture}

Angiosarcoma predominantly shows a diffuse epithelioid morphology, with predominantly solid architecture. Tumour cells are large, polygonal or rounded, with abundant eosinophilic glassy cytoplasm and large vesicular nuclei with prominent eosinophilic nucleoli. Some hyaline globules may be observed within the cytoplasm (figure 9). Solid areas may be associated with focal zones characterized by vasoformative architecture, with vascular channels lined by neoplastic endothelium forming intraluminal buds. Epithelioid cells may be arranged in nests, clusters, papillae, and vascular channels. In cases in which the histological pattern is characterized by complex anastomosing vascular structures, lined by plump epithelioid endothelial cells and a slit-like lumen, the true vascular nature of tumour cells may be difficult to recognize. Rare cases of EAS are characterized by a mixed epithelioid and spindled pattern. Mitotic activity is variable, ranging from 1 to 55 mitotic figures per 10 high power field. Atypical mitotic figures are often found (figure 10). Necrosis is detected in about $50 \%$ of cases. In cases with a predominant solid growth pattern, only intracytoplasmic vacuoles, with occasional blood red cells inside, can represent a clue for a correct diagnosis (34) (figure 11) (table V).

\section{Immunohistochemistry}

At immunohistochemistry, tumor cells are immunoreactive for vascular markers, with CD31, ERG (figure $12 \boldsymbol{a}), \mathrm{D} 2-40$ and FLI-1 offering the highest sensitivity. In contrast with EHE, many angiosarcomas with an epithelioid appearance do not show a significant immunostaining for CD34 (figure $12 \boldsymbol{b}$ ), which contrasts with the strong reactivity for CD31 (15). Cytokeratin expression may be found in two thirds of the cases, whereas and epithelial membrane antigen was positive in $25 \%$ of the cases. SMA positive cuffs are usually lacking (78). Aberrant expression of INSM1 can be seen in a subset of angiosarcomas often with diffuse labeling with diagnostic confusion (79) (table VI).

\section{Genetics}

Whereas most radiation-induced angiosarcomas show MYC gene amplifications, with a subset of cases harboring KDR, PTPRB, and PLCG1 mutations, the genetic abnormalities of most primary angiosarcomas, including the epithelioid variant remain undefined (80). Recently, the finding of CIC -rearrangement in angiosarcoma has been associated with lack of vasoformation, a solid growth pattern and with the epithelioid variant of angiosarcoma (81) (table VII).

\section{Differential diagnosis}

EAS are often confused with poorly differentiated carcinoma, melanoma, epithelioid sarcoma, and anaplastic large cell lymphoma but in this cases immunohistochemistry is relevant. The most important differential diagnosis is epithelioid sarcoma: nuclear SMACB1 (INI-1) protein expression is preserved in angiosarcomas. Morphologically, epithelioid angiosarcoma differs from other epithe- 


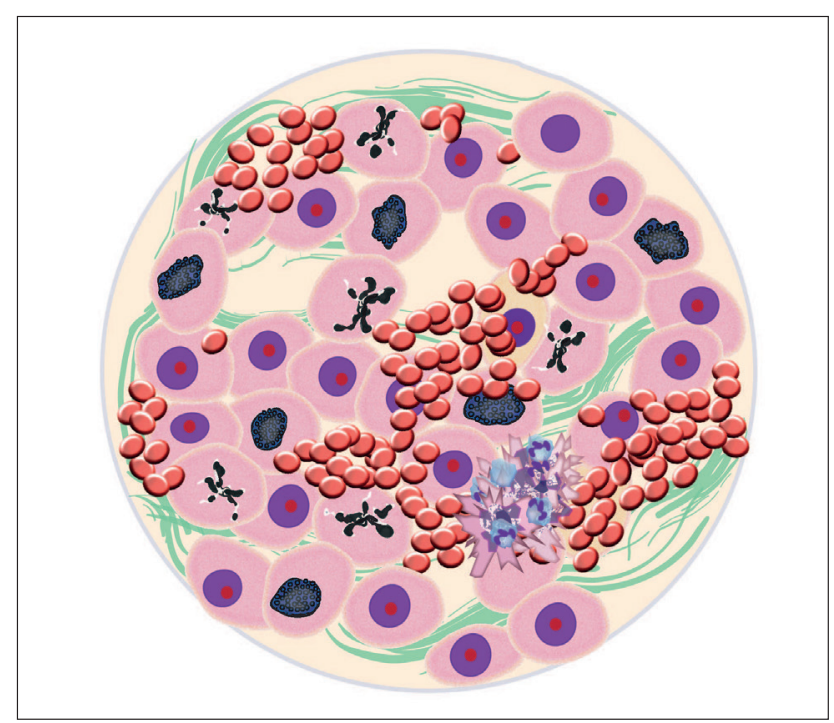

Figure 9. EAS: schematic representation shows polygonal or rounded cells, with abundant eosinophilic glassy cytoplasm and large nuclei with prominent eosinophilic nucleoli, atypical mitotic figures, necrosis.

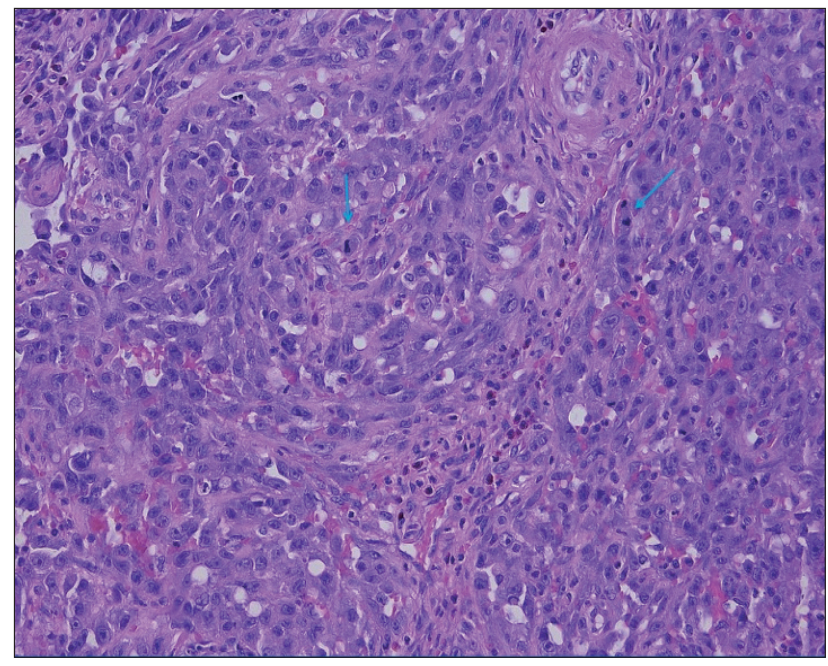

Figure 10. EAS (HE, 20HPF): large epithelioid cells in solid nest; mitotic figures are frequent (arrows).

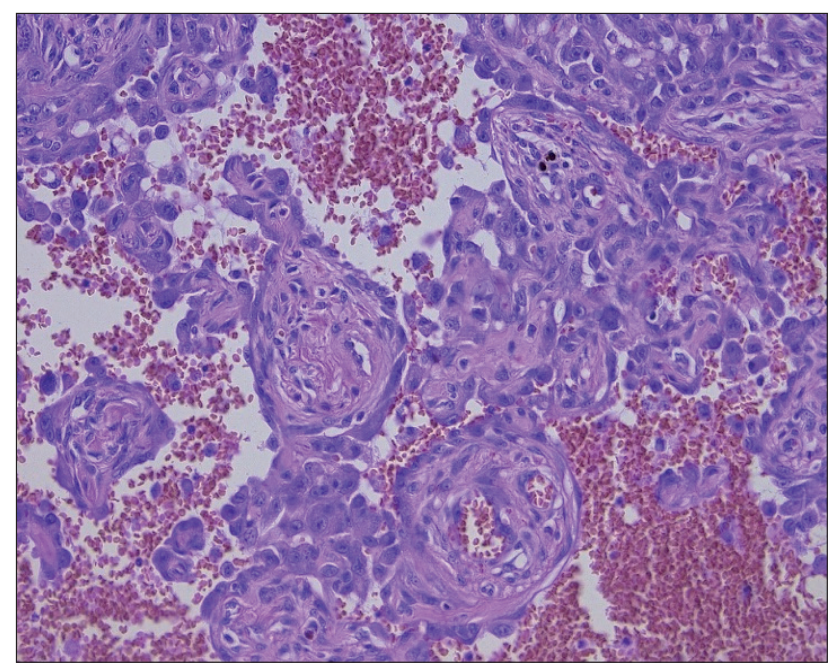

Figure 11. EAS (HE, 4OHPF): tumor cells may be separated by extravasated red blood cells. lioid vascular tumors for marked cytologic atypia, mitotic activity, and tumor necrosis (82).

\section{Prognosis}

These tumours are very aggressive, half of the patients die within one year.

\section{Therapy}

Data on treatment modalities for EAS are limited to retrospective studies and case series. Aggressive surgical excision, radiotherapy and/or chemotherapy is the treatment of choice for resectable EAS, although there is no compelling evidence for adjuvant chemotherapy and radiotherapy. High dose adjuvant radiotherapy (> $50 \mathrm{~Gy}$ ) and wide treatment field (considered in non-radiation-induced cases) are recommended due to the high risk of local recurrence. No formal radiotherapy trials have been done, but retrospective studies suggest that it improves local control and survival $(83,84)$.

EAS have high malignant and strong invasiveness, with a high tendency for both local recurrence and distant metastasis and the prognosis is very poor (85-87). Disease control is the objective in metastatic angiosarcoma, with published rates between 3 months and 7 months (33) and a median overall survival (OS) rate of 14 months to 18 months (34). In both adults and children, 5-year OS rates between $20 \%$ and $35 \%$ are reported (11).

To date, no effective standardized treatment regimen is available for patients with recurrence/metastatic EAS. The multimodality approach consisting of surgery, radiotherapy, chemotherapy and targeted therapy produces better outcomes regard-

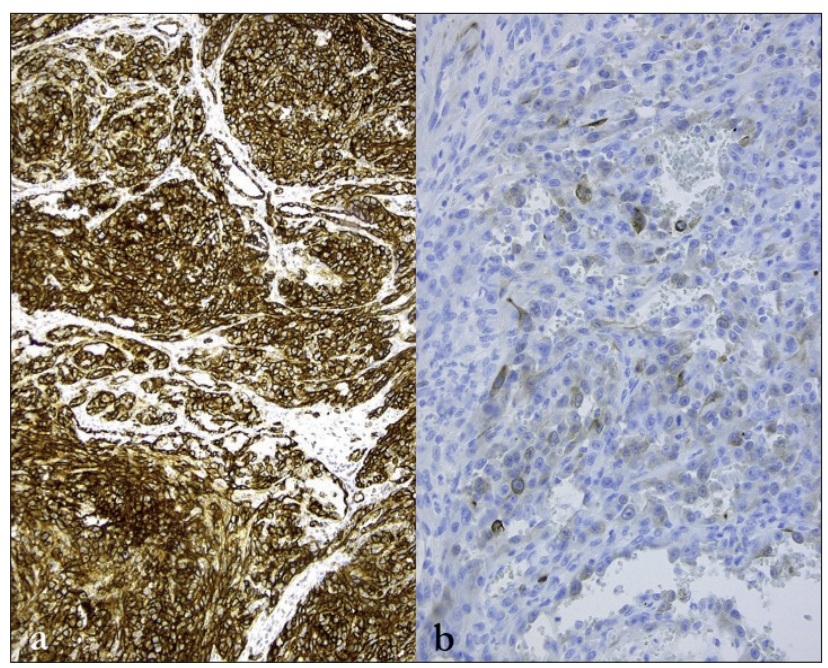

Figure $12 \boldsymbol{a}$. EAS: immunoistochemistry expression of ERG; $\boldsymbol{b}$. immunoistochemistry expression of D2-40 (40HPF). 
less of the location of the tumor $(88,89,85)$.

The association of doxorubicin with ifosfamide versus single agent doxorubicin was related to better survival (90).

In the prospective phase 2 ANGIOTAX study, paclitaxel showed a partial response in $18.5 \%$ of patients ( $n=5$ ) with a PFS of 4 months. In this study weekly paclitaxel demonstrates better response rates for angiosarcoma than doxorubicin, the firstline agent for soft tissue sarcoma (91). However, no significant difference in PFS between treatment groups is reported. Unfortunately, even in combination with target agents such as bevacizumab response rates remained disappointing (92), (93-95). In recent years, next-generation technologies have been introduced in identifying individualized targeted therapy for angiosarcoma, including the anti-VEGFR therapy and the mTOR inhibitors such as everolimus (35). Reports of complete remission after the combined use of preoperative radiation therapy and bevacizumab, followed by surgery, have been described (96).

Anti-VEGF therapies have been found to suppress growth and act synergistically with radiation in many human tumor lines (97-99). Both sorafenib, a small molecule inhibiting BRAF and VEGFR, and pazopanib, inhibiting VEGFR, PDGFR showed potential benefit for EAS treatment (100-102).

The identification of Phospholipase Gamma1 (tPL(G1-R707Q) mutation may confer VEGFR2-independent signaling, thus causing resistance against VEGF(R)-directed therapies (36). Zhang et al reported two cases with recurrence/metastatic EA, who received everolimus after failure of surgery, radiotherapy, chemotherapy or interventional therapy. Both cases obtained clinical benefit within 1 week and were evaluated as partial response (PR). PFS was nearly 12.0 and 6.0 months, respectively. OS was 18.0 and 10.0 months, respectively. The main adverse event was stomatitis syndrome (grade 1-2), which was well controllable and tolerable (85). Recently, the role of immunotherapy has been investigated in EAS. A 63-year-old man with EAS of the nose progressing in the face and liver 4 years after surgery and refractory to nab-paclitaxel, surgery, and radioembolization, was treated with off-label pembrolizumab, an anti-PD1 antibody. EAS was found to express PD-L1 and he was administered pembrolizumab $2 \mathrm{mg} / \mathrm{kg}$ every 21 days for 13 cycles. The patient had a sustained response, with significant shrinkage of liver and facial metastases and did not develop PD during the 8 months off therapy due to hepatitis occurrence requiring decreasing doses of prednisone (103). Further investigation is required to assess the role of immune checkpoint inhibitors in EAS.

\section{CONCLUSIONS}

The diagnosis of vascular tumours represents a complex and very difficult area in the field of soft tissue tumours. Epithelioid vascular tumours pose a particular challenge, mainly due to the epithelioid morphology of tumour cells. In clinical practice, vascular neoplasms characterized by an epithelioid appearance may mimic and can be misdiagnosed as a variety of other tumour entities, including metastatic carcinoma or epithelioid sarcoma. Furthermore, the differential diagnosis of the multiple variants of epithelioid vascular tumours here reported can be difficult and may have relevant clinical consequences, given the marked differences in prognosis and therapy. In this review, the most important clinical, morphologic, immunohistochemical and molecular genetic features useful for a correct diagnosis of epithelioid vascular tumours have been reported. Regarding the immunohistochemical markers to be used to detect the endothelial nature of epithelioid cells, CD31 and ERG are the most useful, although they are not specific $(104,41)$. CD31 also labels macrophages and ERG expression can be seen in half of the epithelioid sarcomas and prostate carcinomas as well as in some Ewing sarcomas and chloromas, and in normal lymphocytes. The knowledge of some key histological features of this group of soft tissue tumours, associated with an optimal use of immunohistochemical markers, may represent the clue for a correct diagnosis of vascular tumours with an epithelioid appearance, allowing the optimal therapeutic approach to these challenging tumours.

\section{ETHICS}

\section{Fundings}

There were no institutional or private fundings for this article.

\section{Conflict of interests}

The autors have declared no conflict of interests. 


\section{Availability of data and materials}

All the data supporting the findings of this study are available within the article and can be shared just before a reasonable request to the corresponding author.

\section{Code availability}

N/A

\section{REFERENCES}

1. WHO Classification of Tumours Editorial Board. WHO Classi- fication of Tumours of Soft Tissue and Bone, $5^{\text {th }}$ ed. Lyon, France: IARC Press; 2020.

2. Sbaraglia M, Bellan $E$, Dei Tos AP. The 2020 WHO Classification of Soft Tissue Tumours: news and perspectives. Pathologica 2020;113(2):70-84.

3. Hornick JL, Fletcher CDM. Pseudomyogenic Hemangioendothelioma: A Distinctive, Often Multicentric Tumor With Indolent Behavior. Am J Surg Pathol 2011;35(2):190-201.

4. Suurmeijer AJH, Dickson BC, Swanson D, Sung YS, Zhang L, Antonescu CR. Variant WWTR1 gene fusions in epithelioid hemangioendothelioma - A genetic subset associated with cardiac involvement. Genes Chromosomes Cancer 2020;59(7):389-95.

5. Fetsch JF, Weiss SW. Observations concerning the pathogenesis of epithelioid hemangioma (angiolymphoid hyperplasia). Mod Pathol 1991;4(4):449-55.

6. Ismail M, Damato S, Freeman A, Nigam R. Epithelioid hemangioma of the penis: case report and review of literature. J Med Case Reports 2011;5(1):260.

7. Enzinger and Weiss's soft tissue tumors. Goldblum JR, Folpe AL, Weiss SW. $7^{\text {th }}$ edition, Elsevier 2020.

8. Miettinen $M$, Wang $Z-F$, Paetau $A$, et al. ERG Transcription Factor as an Immunohistochemical Marker for Vascular Endothelial Tumors and Prostatic Carcinoma. Am J Surg Pathol 2011;35(3):432-41.

9. Papke DJ, Hornick JL. What is new in endothelial neoplasia? Virchows Arch 2020;476(1):17-28.

10. Hung YP, Fletcher CDM, Hornick JL. FOSB is a Useful Diagnostic Marker for Pseudomyogenic Hemangioendothelioma. Am J Surg Pathol 2017;41(5):596-606.

11. Ortins-Pina $A$, Llamas-Velasco $M$, Turpin $S$, Soares-de-Almeida L, Filipe P, Kutzner H. FOSB

\section{Authors' contribution}

All the authors contributed equally to conception, data collection, analysis and writing of this paper.

\section{Ethical approval}

N/A

immunoreactivity in endothelia of epithelioid hemangioma (angiolymphoid hyperplasia with eosinophilia). J Cutan Pathol 2018;45(6):395-402.

12. Antonescu CR, Huang SC, Sung YS, et al. Novel GATA6-FOXO1 fusions in a subset of epithelioid hemangioma. Mod Pathol 2020. Available from http://www.nature.com/articles/s41379020-00723-4. Last access Jan 9, 2021.

13. Antonescu CR, Chen HW, Zhang L, Sung YS, et al. ZFP36-FOSB fusion defines a subset of epithelioid hemangioma with atypical features: ZFP36-FOSB FUSION. Gen Chromosomes Cancer 2014;53(11):951-9.

14. Shon W, Billings SD. Epithelioid Vascular Tumors: A Review. Adv Anat Pathol 2019;26(3):186-97.

15. Hornick JL. Practical Soft Tissue Pathology: A Diagnostic Approach E-Book: A Volume in the Pattern Recognition Series. Elsevier Health Sciences 2013.

16. Tsikopoulos K, Perdikakis E, Georgiannos D, Bisbinas I. Epithelioid hemangioma of the scapula treated with chemoembolization and microwave ablation: A case report. Acta Orthopaedica et Traumatologica Turcica 2018;52(2):157-61.

17. Nangia R, Puri A, Gupta R, Bansal S, Negi A, Chauhan I. Epithelioid Hemangioma of Lingual Alveolar Mucosa: An Immunohistochemical Case Report. Case Reports in Medicine 2014;2014:1-5.

18. Wiggins CJ, Dibbs RP, Bartlett EL, Ashton DJ, Maricevich RS. Atypical presentation and management of an epithelioid hemangioma: a case report and review of the literature. Ann Pediatr Surg 2020;16(1):53.

19. Niimi R, Matsumine A, Kusuzaki K, et al. Epithelioid hemangioendothelioma after radiotherapy for congenital hemangioma: a case report. Med Oncol 2010;27(1):130-3.

20. Akosa $A B$, Ali MH. Epithelioid haemangioendothelioma of terminal ileum after therapeu- 
tic irradiation. J Clin Pathol 1989;42(8):889-90.

21. Hahn E, Dickson BC, Gupta AA, NofechuMozes S. Case of epithelioid hemangioendothelioma occurring in the postradiation setting for breast cancer. Genes Chromosomes Cancer 2021;60(2):112-5.

22. Attanoos RL. Malignant vascular tumours of the pleura in «asbestos» workers and endothelial differentiation in malignant mesothelioma. Thorax 2000;55(10):860-3.

23. Shin MS, Carpenter JT, Ho KJ. Epithelioid hemangioendothelioma: CT manifestations and possible linkage to vinyl chloride exposure. J Comput Assist Tomogr 1991;15(3):505-7.

24. Gelin M, Van de Stadt J, Rickaert F, et al. Epithelioid hemangioendothelioma of the liver following contact with vinyl chloride. J Hepatol 1989;8(1):99-106.

25. Makhlouf HR, Ishak KG, Goodman ZD. Epithelioid hemangioendothelioma of the liver: a clinicopathologic study of 137 cases. Cancer 1999;85(3):562-82.

26. Clements D, Hubscher S, West R, Elias E, McMaster P. Epithelioid haemangioendothelioma. A case report. J Hepatol 1986;2(3):441-9.

27. Sarma NHHN. Epithelioid haemangioendothelioma of soft tissue after pellet injury. J Clin Pathol 1992;45(7):640-1.

28. Furuta K, Sodeyama T, Usuda S, et al. Epithelioid hemangioendothelioma of the liver diagnosed by liver biopsy under laparoscopy. Am J Gastroenterol 1992;87(6):797-800.

29. Madura C, Sacchidanand S, Barde N, Biligi D. Epithelioid hemangioendothelioma in a Child. J Cutan Aesthet Surg 2013;6(4):232.

30. Doyle LA, Fletcher CDM, Hornick JL. Nuclear Exprmession of CAMTA1 Distinguishes Epithelioid Hemangioendothelioma From Histologic Mimics: Am J Surg Pathol 2016;40(1):94-102.

31. Lee SJ, Yang WI, Chung W-S, Kim SK. Epithelioid hemangioendotheliomas with TFE3 gene translocations are compossible with CAMTA1 gene rearrangements. Oncotarget 2016;7(7):7480-8.

32. Tanas MR, Sboner A, Oliveira AM, et al. Identification of a Disease-Defining Gene Fusion in Epithelioid Hemangioendothelioma. Sci Trans Med 2011;3(98):98ra82-98ra82.

33. Shibuya R, Matsuyama A, Shiba E, Harada $H$, Yabuki K, Hisaoka M. CAMTA1 is a useful immunohistochemical marker for diagnosing epithelioid haemangioendothelioma. Histopathology 2015;67(6):827-35.
34. Ko JS, Billings SD. Diagnostically Challenging Epithelioid Vascular Tumors. Surg Pathol Clin 2015;8(3):331-51.

35. Deyrup AT, Tighiouart M, Montag AG, Weiss SW. Epithelioid Hemangioendothelioma of Soft Tissue: A Proposal for Risk Stratification Based on 49 Cases: Am J Surg Pathol 2008;32(6):924-7.

36. Shibayama T, Makise N, Motoi T, et al. Clinicopathologic Characterization of Epithelioid Hemangioendothelioma in a Series of 62 Cases: A Proposal of Risk Stratification and Identification of a Synaptophysin-positive Aggressive Subset. Am J Surg Pathol 2021;45(5):616-26.

37. Stacchiotti $S$, Miah AB, Frezza AM, et al. Epithelioid hemangioendothelioma, an ultra-rare cancer: a consensus paper from the community of experts. ESMO Open 2021;6(3):100170.

38. Stacchiotti $S$, Miah AB, Frezza AM, et al. Epithelioid hemangioendothelioma, an ultra-rare cancer: a consensus paper from the community of experts. ESMO Open 2021;6(3):100170.

39. Albakr A, Schell M, Drew B, Cenic A. Epithelioid hemangioendothelioma of the spine: case report and review of the literature. J Spine Surg 2017;3(2):250-9.

40. PDQ Pediatric Treatment Editorial Board. Childhood Vascular Tumors Treatment (PDQ®): Health Professional Version. In: PDQ Cancer Information Summaries. Bethesda (MD): National Cancer Institute (US) 2002. [Available from http:// www.ncbi.nlm.nih.gov/books/NBK343452/. Last access Feb 26, 2021.

41. Agulnik M, Yarber JL, Okuno SH, et al. An open-label, multicenter, phase II study of bevacizumab for the treatment of angiosarcoma and epithelioid hemangioendotheliomas. Ann Oncol 2013;24(1):257-63.

42. Chevreau C, Le Cesne A, Ray-Coquard I, et al. Sorafenib in patients with progressive epithelioid hemangioendothelioma: A phase 2 study by the French Sarcoma Group (GSF/GETO). Cancer July 15, 2013;119(14):2639-44.

43. Frezza AM, Ravi V, Lo Vullo S, et al. Systemic therapies in advanced epithelioid haemangioendothelioma: A retrospective international case series from the World Sarcoma Network and a review of literature. Cancer Med 2021;10(8):2645-59.

44. Cournoyer E, Al-Ibraheemi A, Engel E, Chaudry G, Stapleton S, Adams DM. Clinical characterization and long-term outcomes in pediatric epithelioid hemangioendothelioma. Pediatr Blood 
Cancer 2020;67(2). Available from https:// onlinelibrary.wiley.com/doi/abs/10.1002/ pbc.28045. Last access Feb 26, 2021.

45. Stacchiotti S, Simeone N, Lo Vullo S, et al. Activity of sirolimus in patients with progressive epithelioid hemangioendothelioma: A case-series analysis within the Italian Rare Cancer Network. Cancer 2021;127(4):569-76.

46. Semenisty V, Naroditsky I, Keidar Z, Bar-Sela G. Pazopanib for metastatic pulmonary epithelioid hemangioendothelioma-a suitable treatment option: case report and review of anti-angiogenic treatment options. BMC Cancer 2015;15(1):402.

47. Sardaro A, Bardoscia L, Petruzzelli MF, PortaIuri M. Epithelioid hemangioendothelioma: an overview and update on a rare vascular tumor. Oncol Rev 2014. Available from https://www. oncologyreviews.org/site/article/view/259. Last access Feb 26, 2021.

48. Zhang XQ, Chen $H$, Song $S$, Qin $Y$, Cai LM, Zhang F. Effective combined therapy for pulmonary epithelioid hemangioendothelioma: A case report. WJCC 2020;8(10):2009-15.

49. Otte J-B, Zimmerman A. The role of liver transplantation for pediatric epithelioid hemangioendothelioma. Pediatric Transplantation 2010;14(3):295-7.

50. Panagopoulos I, Lobmaier I, Gorunova L, Heim S. Fusion of the Genes WWTR1 and FOSB in Pseudomyogenic Hemangioendothelioma. Cancer Genomics Proteomics 2019;16(4):293-8.

51. Ye C, Yu X, Zeng J, Liu H, Dai M. Pseudomyogenic hemangioendothelioma secondary to fibrous dysplasia of the left lower extremity in a 14-year-old female: a case report. World J Surg Onc 2016;14(1):198.

52. Inyang A, Mertens F, Puls F, et al. Primary Pseudomyogenic Hemangioendothelioma of Bone: The American J Surg Pathol 2016;40(5):587-98.

53. Caballero GA, Roitman PD. Pseudomyogenic Hemangioendothelioma (Epithelioid Sarcoma-Like Hemangioendothelioma). Archives of Pathology \& Laboratory Medicine 2020;144(4):529-33.

54. Walther C, Tayebwa J, Lilljebjörn $\mathrm{H}$, et al. A novel SERPINE1-FOSB fusion gene results in transcriptional up-regulation of FOSB in pseudomyogenic haemangioendothelioma: SERPINE1-FOSB fusion in pseudomyogenic haemangioendothelioma. J Pathol 2014;232(5):534-40.

55. Ansai S, Morimoto M, Akaishi S. Pseudomyo- genic Hemangioendothelioma. J Nippon Med Sch 2019;86(2):126-30.

56. Al-Qaderi A, Mansour AT. Pseudomyogenic Hemangioendothelioma. Arch Pathol Lab Med 2019;143(6):763-7.

57. Wei J, Liao Z, Zhao G, et al. Clinicopathological features of pseudomyogenic hemangioendothelioma and precision therapy based on whole exome sequencing. Cancer Communications 2020;40(4):197-201.

58. Joseph J, Wang W, Patnana M, R, et al. Cytotoxic and targeted therapy for treatment of pseudomyogenic hemangioendothelioma. Clin Sarcoma Res 2015;5(1):22.

59. Stuart LN, Gardner JM, Lauer SR, Monson DK, Parker DC, Edgar MA. Epithelioid sarcoma-like (pseudomyogenic) hemangioendothelioma, clinically mimicking dermatofibroma, diagnosed by skin biopsy in a 30-year-old man: ESHE mimicking dermatofibroma. J Cutan Pathol 2013;n/a-n/a.

60. Gabor KM, Sapi Z, Tiszlavicz LG, Fige A, Bereczki C, Bartyik K. Sirolimus therapy in the treatment of pseudomyogenic hemangioendothelioma. Pediatr Blood Cancer 2018;65(2).

61. Ozeki M, Nozawa A, Kanda K, et al. Everolimus for Treatment of Pseudomyogenic Hemangioendothelioma. J Pediatr Hematol Oncol 2017;39(6):e328-31.

62. van IJzendoorn DGP, Sleijfer S, Gelderblom $\mathrm{H}$, et al. Telatinib Is an Effective Targeted Therapy for Pseudomyogenic Hemangioendothelioma. Clin Cancer Res 2018;24(11):2678-87.

63. Shon W, Jenkins SM, Ross DT, et al. Angiosarcoma: a study of 98 cases with immunohistochemical evaluation of TLE3, a recently described marker of potential taxane responsiveness. J Cutaneous Pathol 2011;38(12):961-6.

64. Wang G, Black PC, Skinnider BF, Hayes MM, Jones EC. Post-radiation epithelioid angiosarcoma of the urinary bladder and prostate. CUAJ 2016;10(5-6):197.

65. Tabareau-Delalande F, de Muret A, Miquelestorena-Standley E, Decouvelaere A-V, de Pinieux G. Cutaneous Epithelioid Clear Cells Angiosarcoma in a Young Woman with Congenital Lymphedema. Case Reports in Pathology 2013;2013:1-6.

66. Kojiro M, Nakashima T, Ito Y, Ikezaki H. Pathomorphological study on thorotrast-induced hepatic malignancies. Strahlentherapie Sonderb 1985;80:119-22. 
67. Popper H, Thomas LB, Telles NC, Falk H, Selikoff IJ. Development of hepatic angiosarcoma in man induced by vinyl chloride, thorotrast, and arsenic. Comparison with cases of unknown etiology. Am J Pathol 1978;92(2):349-76.

68. Forbes A, Portmann B, Johnson P, Williams R. Hepatic sarcomas in adults: a review of 25 cases. Gut 1987;28(6):668-74.

69. Salgado M, Sans M, Forns $X$, et al. Hepatic angiosarcoma: a report of a case associated with treatment with arsenic salts and a review of the literature. Gastroenterol Hepatol 1995;18(3):132-5.

70. Livaditou A, Alexiou G, Floros D, Filippidis T, Dosios T, Bays D. Epithelioid angiosarcoma of the adrenal gland associated with chronic arsenical intoxication? Pathol Res Pract 1991;187(23):284-9.

71. Pimentel JC, Menezes AP. Liver disease in vineyard sprayers. Gastroenterology 1977;72(2):275-83.

72. Falk H, Thomas LB, Popper H, Ishak KG. Hepatic angiosarcoma associated with androgenic-anabolic steroids. Lancet 1979;2(8152):1120-3.

73. Lin YH, Lin CC, Concejero AM, Yong CC, Kuo FY, Wang CC. Surgical experience of adult primary hepatic sarcomas. World J Surg Onc 2015;13(1):87.

74. Deyrup AT, Miettinen M, North PE, et al. Pediatric Cutaneous Angiosarcomas: A Clinicopathologic Study of 10 Cases. Am J Surg Pathol 2011;35(1):70-5.

75. Dey B, Srinivas BH, Badhe B, et al. Malignant Epithelioid Soft Tissue Tumours - A Pathologist's Perspective With Review of Literature. Cureus 2020. Available from https://www.cureus.com/articles/46755-malignant-epithelioid-soft-tissue-tumours--a-pathologists-perspective-with-review-of-literature. Last access Feb 26, 2021.

76. Ayadi L, Khabir A. Pediatric angiosarcoma of soft tissue: a rare clinicopathologic entity. Arch Pathol Lab Med 2010;134(3):481-5.

77. Grassia KL, Peterman CM, lacobas I, et al. Clinical case series of pediatric hepatic angiosarcoma. Pediatr Blood Cancer 2017;64(11):e26627.

78. Lee HE, Torbenson MS, WU T-T, Chandan VS. Aberrant keratin expression is common in primary hepatic malignant vascular tumors: A potential diagnostic pitfall. Ann Diagnos Pathol 2020;49:151589.

79. Warmke LM, Tinkham EG, Ingram DR, Lazar AJ, Panse G, Wang WL. INSM1 Expression in Angiosarcoma. Am J Clin Pathol 2020;aqaa168.

80. Manner J, Radlwimmer B, Hohenberger P, et al. MYC high level gene amplification is a distinctive feature of angiosarcomas after irradiation or chronic lymphedema. Am J Pathol 2010;176(1):34-9.

81. Huang SC, Zhang L, Sung YS, et al. Recrrent CIC Gene Abnormalities in Angiosarcomas: A Molecular Study of 120 Cases With Concurrent Investigation of PLCG1, KDR, MYC, and FLT4 Gene Alterations. Am J Surg Pathol 2016;40(5):645-55.

82. Shon W, Billings SD. Epithelioid Vascular Tumors: A Review. Adv Anat Pathol 2019;26(3):186-97.

83. Abraham JA, Hornicek FJ, Kaufman AM, et al. Treatment and Outcome of 82 Patients with Angiosarcoma. Ann Surg Oncol 2007;14(6):1953-67.

84. Hara T, Miyoshi A, Kamei $Y$, et al. Epithelioid Angiosarcoma Arising from a Huge Leiomyoma: A Case Report and a Literature Review. Case Reports Obstet Gynecol 2018;2018:1-6.

85. Zhang SL, Liang L, Ji Y, Wang ZM, Zhou YH. The benefit of everolimus in recurrent/epithelioid angiosarcoma patients: Case reports and literature review. Oncotarget 2017;8(55):95023-9.

86. Holden CA, Spittle MF, Jones EW. Angiosarcoma of the face and scalp, prognosis and treatment. Cancer 1987;59(5):1046-57.

87. Willers H, Hug EB, Spiro IJ, Efird JT, Rosenberg $A E$, Wang CC. Adult soft tissue sarcomas of the head and neck treated by radiation and surgery or radiation alone: Patterns of failure and prognostic factors. In J Rad Oncol Biol Phys ottobre 1995;33(3):585-93.

88. Guadagnolo BA, Zagars GK, Araujo D, Ravi V, Shellenberger TD, Sturgis EM. Outcomes after definitive treatment for cutaneous angiosarcoma of the face and scalp. Head Neck 2011;33(5):661-7.

89. Torres KE, Ravi V, Kin K, et al. Long-Term Outcomes in Patients with Radiation-Associated Angiosarcomas of the Breast Following Surgery and Radiotherapy for Breast Cancer. Ann Surg Oncol 2013;20(4):1267-74.

90. Florou V, Wilky BA. Current and Future Directions for Angiosarcoma Therapy. Curr Treat Options in Oncol 2018;19(3):14.

91. Penel N, Bui BN, Bay JO, et al. Phase II Trial of Weekly Paclitaxel for Unresectable Angiosarcoma: The ANGIOTAX Study. JCO 2008;26(32):5269-74.

92. Akerley W, Herndon JE, Egorin MJ, et al. Weekly, high-dose paclitaxel in advanced lung carcinoma: A Phase II study with pharmacokinetics 
by the Cancer and Leukemia Group B. Cancer 2003;97(10):2480-6.

93. Arai $W$, Hosoya $Y$, Hyodo $M$, et al. Doxifluridine combined with weekly paclitaxel for second-line treatment in patients with gastric cancer resistant to TS-1. Int J Clin Oncol 2007;12(2):146-9.

94. Lebellec $L$, Bertucci $F$, Tresch-Bruneel E, et al. Prognostic and predictive factors for angiosarcoma patients receiving paclitaxel once weekly plus or minus bevacizumab: an ancillary study derived from a randomized clinical trial. BMC Cancer 2018;18(1):963.

95. Ray-Coquard IL, Domont J, Tresch-Bruneel E, et al. Paclitaxel Given Once Per Week With or Without Bevacizumab in Patients With Advanced Angiosarcoma: A Randomized Phase II Trial. JCO 2015;33(25):2797-802.

96. Koontz BF, Miles EF, Rubio MAD, et al. Preoperative radiotherapy and bevacizumab for angiosarcoma of the head and neck: Two case studies. Head Neck 2008;30(2):262-6.

97. Asano M, Yukita A, Suzuki H. Wide Spectrum of Antitumor Activity of a Neutralizing Monoclonal Antibody to Human Vascular Endothelial Growth Factor. Japan J Cancer Res 1999;90(1):93-100.

98. Gorski DH, Beckett MA, Jaskowiak NT, et al. Blockage of the vascular endothelial growth factor stress response increases the antitumor effects of ionizing radiation. Cancer Res 1999;59(14):3374-8.

99. Lee CG, Heijn M, di Tomaso E, et al. Anti-Vascular endothelial growth factor treatment augments tumor radiation response under normoxic or hypoxic conditions. Cancer Res 2000;60(19):5565-70.

100. Penel N, Ray-Coquard I, Bal-Mahieu C, et al. Low level of baseline circulating VEGF-A is associated with better outcome in patients with vascular sarcomas receiving sorafenib: an ancillary study from a phase II trial. Targ Oncol 2014;9(3):273-7.

101. Hoang NT, Acevedo LA, Mann MJ, Tolani B. A review of soft-tissue sarcomas: translation of biological advances into treatment measures. CMAR 2018;10:1089-114.

102. Ravi V, Sanford EM, Wang W-L, et al. Antitumor Response of VEGFR2- and VEGFR3-Amplified Angiosarcoma to Pazopanib. J Natl Compr Canc Netw 2016;14(5):499-502.

103. Sindhu S, Gimber LH, Cranmer L, McBride A, Kraft AS. Angiosarcoma treated successfully with anti-PD-1 therapy - a case report. J immunother cancer 2017;5(1):58.

104. HornickJL. Novel uses of immunohistochemistry in the diagnosis and classification of soft tissue tumors. Mod Pathol 2014;27 Suppl 1:S47-63. 